\title{
Cartilage damage: a review of surgical repair options and outcomes
}

\author{
Taylor Pettit ${ }^{1}$, Taylor Kolvek ${ }^{2}$ and Micheal Langworthy ${ }^{3 *}$ \\ ${ }^{1}$ Orthopedic Physicians Assistant, Southcoast Physicians Group, Dartmouth MA, USA \\ ${ }^{2}$ Bachelors of Arts in Biology, Roger Williams University, Bristol RI, USA \\ ${ }^{3}$ Chairman of Orthopedics, Southcoast Physicians Group, Dartmouth MA, USA
}

\section{Cartilage damage and generalized health}

Initial degenerative changes in articular cartilage are typically silent. However, once symptoms appear, $\mathrm{OA}$ is a chronic progressive condition that causes pain and increasing disability $[1,2]$. After accounting for mechanical disorders, OA has a high rate of comorbidities (67\%) in the general population, including diabetes and obesity [3]. Over the past decade, increasing interest in these comorbidities has led to Association of OA with cardiovascular disorders and hypertension $[3,4]$. The term "metabolic syndrome" has been applied to the combination of obesity, diabetes, hypertension, and cardiovascular disease [4].

A study of the personnel in the Brazilian Navy found 30\% of members had 2 or more risk factors (abdominal obesity, low HDL cholesterol, high fasting glycemia, high triglycerides, and high blood pressure) for metabolic syndrome [5]. In Finland, the high prevalence rate of metabolic syndrome in young obsess men decreased by $40 \%$ with the physical exercise required for military service [4]. With such a high rate of comorbidities, OA is a serious public-health concern, and with a high numbers of exercise injuries leading to posttraumatic $\mathrm{OA}$, expenditures of OA related healthcare cost forward to stable trips are rising. Repair of the damaged joint can have a profound affect of improving mobility and overall fitness of an individual (Figure 1).

\section{Osteoarthritis pathophysiology}

Molecular, mechanical, and traumatic events can all predispose a person for OA [6]. Genetic factors and the effects of aging can also

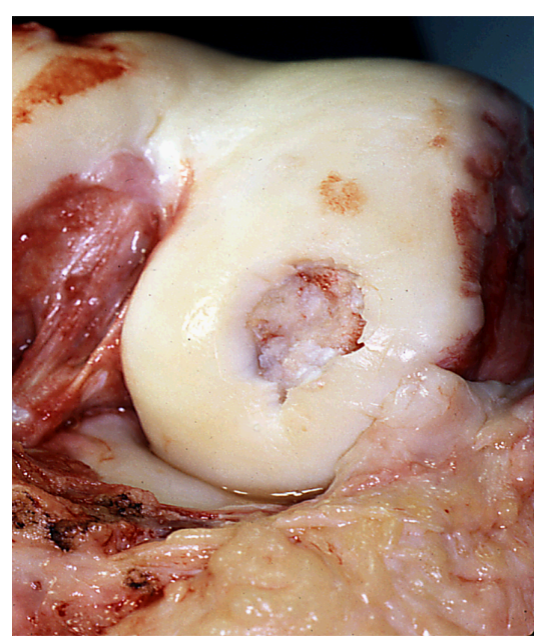

Figure 1. Damaged cartilage of femur play a role [1]. OA is considered disease of the whole joint, affecting all joint tissues as they communicate with each other by releasing and responding to various signaling molecules [7]. Although the major molecules of articular cartilage are collagen and aggrecan, chondrocytes of the unique cells and cartilage that maintained joint hemostasis [2,7]. Always typically characterized by degeneration of type II collagen, a deep crease in the amount and size of aggrecan, and the diminished ability chondrocytes to remodel and repair the cartilage matrix [1]. With the disruption of type II collagen and loss of aggrecan, water content in the joint increases and the cartilage matrix loses tensile strength [1]. When responding to inflammation in stress, osteoarthritic chondrocytes produce matrix degrading enzymes, which further disrupt the joint matrix environment [7]. These molecular changes to the cartilage reduce the ability of cartilage to disperse the load, minimize friction, and allow movement of the joint [8].

Other joint factors besides the cartilage also appeared to contribute to the osteoarthritic process. The elasticity of the synovial fluid, which lubricated to protect the knee joint, decreases with age and is more dramatic with OA [9]. The fluid of the knee joint is viscous, in part, because of the HA content; but in OA, the knee has about half the amount of HA as a healthy adult knee [9]. Intuitively, was synovial fluid should cause an increase in the friction coefficient [10], which would compromise the ability of the synovial fluid to lubricate and protect the joint. Recently Caligaris and colleagues demonstrated that the friction coefficient of human tibiofemoral cartilage did not increase with increasing grades of OA, but did increase with decreasing molecular weight of osteoarthritic synovial fluid [10]. From scientific viewpoint, they concluded the intra-articular injections of high molecular weight synovial fluid may produce a statistically significant decrease in the cartilage friction coefficient [10].

Mechanical factors also contribute to OA through joint instability and misalignment [1]. Muscular weakness such as from the quadriceps muscle can increase OA progression secondary to decreased joint stability and the inability of the muscle to assistant shock absorption of the joint during gait. Military fibrillations require high activity levels at demand increased use of knees, placing troops at a high risk for any injuries to. The general population lifetime risk of developing always significantly higher for those with a history of knee injury (57\%) compared with those without any injuries (42\%) [11]. And a recent

Correspondence to: Micheal Langworthy, Chairman of Orthopedics, Southcoast Physicians Group, Dartmouth MA, USA, E-mail: langworthym@southcoast.org

Received: May 28, 2017; Accepted: July 10, 2017; Published: July 13, 2017 
study posterior medical way in the military, repairing colleagues noted that all warriors (100\%) who sustaining injuries, subsequently developed OA [12].

Altered mechanics because of injury may be direct or indirect direct. Direct articular cartilage impact can disrupt the knee meniscus, ligaments, cartilage, and bone [13]. The long-term effects of cruciate and major meniscal injury are well known [13]. Even with surgical repair, a disrupted anterior cruciate ligament could not restore knee kinematics and joint contact mechanics [14]. Because a military such as physically active population, the 10 times greater incident rate of anterior cruciate ligament injuries reported for military personnel compared with other non-military populations is not unexpected [15]. Jones and colleagues reported that incidence for meniscal injury increased approximately $60 \%$ for every $5 y e a r$ age group to. In fact, approximately $50 \%$ of patients who underwent meniscal surgery developed knee OA within 10-20 years [13].

Cellular changes accompany with mechanical changes to the joint that occur with injury [16]. Following sublethal injury to chondrocytes, the combination of apoptosis and mechanically driven shifts in chondrocyte phenotype leads to stress-induced signaling cascades inactivation of inflammatory mediators $[7,16]$. Other genes involved an injury response including protein kinases that promote apoptosis [16]. The joints response to injury will vary based on which jeans are activated, but the increased expression of inflammatory and apoptotic signals can lead to more rapid articular cartilage degeneration $[7,16]$. Thus, cellular responses to injury induced inflammatory responses that intern Perpetua cartilage degeneration and weaken the ability to repair the joint [7]. These changes are likely to further contribute to the development of progression of OA [7].

To reduce the impact of post traumatic OA, current research efforts her examining ways to preserve and protect the joint, to repair damaged articular cartilage, and to prevent cell death after injury [17].

Pain from OA is a potent motivator for people to seek treatment further OA. Patients typically describe pain that begins gradually and worsens over time. The pain in the joint is not produced from the cartilage because cartilage does not have any nerve endings [18]. With movement, joint send signals to sensory nerves [1]. In OA, the signaling is increased and is interpreted as pain in the Central nervous system [1]. Discomfort from always often hard to localize for patients. They may have OA and 1 portion of the joint, but perceive the pain radiating to the other side of the joint, or up and down the leg.

Synovial inflammation may further promote cartilage distraction or hinder the ability of cartilage to be repaired [7]. The resulting swelling can be very painful, and may decreased range of motion of the joint. Interestingly, this may be protective. Many patients will rest and reduce her activity level because of the swollen joint, which decreased potential damage of the joint.

\section{Biomechanics}

Adult articular cartilage on average experiences about 2 megapascals of force and the hip, knee, and ankle [19-22]. Meniscal or anterior cruciate injury can increase articular forces to well over 8 megapascals which is well beyond the normal load of 1-4 megapascals which could explain a subsequent arthritic degeneration over months and years $[23,24]$. Articular cartilages viscoelastic, which in biology means a prior preoperative tissue that exhibits both viscous and elastic behavior, (creep and stress relaxation); the material stress strain behavior depends on strain rate [25]. Articular cartilage is anisotropic, meaning the intrinsic material properties depend on the matrix orientation and composition as well as the direction in which the cartilages loaded. Split line patterns on the surface of a human femoral condyle using India ink stain reveals the orientation of the fibers and show the anisotropic nature of articular cartilage that should be illustrated. Collagen restricts the swelling pressure of aggrecan and to only $20 \%$ of its capacity to associated water, which is 50 times its weight. The internal pressure within cartilage is 0.5 megapascals ( 75 pounds per square inch) [26].

The 4 zones of cartilage behaves somewhat differently with statically applied strains [27]. The highest axial strain measurements have been found in the transitional zone, however, this was significantly only with respect to the upper and lower radial zones. It is thought that this relatively low axial strain pattern in the lower radial zone is most likely related to high proteoglycan content of this zone and its attachment to the underlying subchondral bone [28]. A constant force we will produce creep and the Deformation from the stressful increase with time so long as the forces maintained.

Undersurface of articular cartilage, the collagen fibers have a tensile strength of 30 megapascals in the young adult. To understand there relevance of this figure, aluminum has a tensile strength of 70 megapascals and nylon has a tensile strength of 80 megapascals [29].

\section{Isolated chondral injuries versus osteoarthrosis}

The concept of the relationship between duration, intensity, frequency of an applied force on articular cartilage is described as an envelope of injury [30]. Single event traumatic episodes tend to produce lesions isolated to a geographic area and are most often associated with a specific injury event. In contrast, conditions that develop slowly and are not associated with trauma are more likely to influence a wider area of the joint. These changes are associated with long-term biochemical changes and affect a larger amount of cartilage around the infected site leading to osteoarthrosis [31]. Articular chondrocytes are generally able to maintain cartilage throughout life by replacing lost or damage matrix that they freshly synthesized material. Synthetic activity is very well regulated and will rapidly increase to well above basal levels in response to cartilage injury. This suggests that synthesis activity is linked to matrix loss through some damage control mechanism. A major stimulator of matrix synthesis is insulin like growth fracture I (IGF-I). Its availability in cartilage is controlled by IGF binding proteins (IGFBPs) that are secreted by chondrocytes. IGFBPs are part of a complex system, terms the IGF-I access that tightly regulates IGF-I activity. The IGFBPs block IGF-I activity by sequestering IGF-I from its cell receptor. The binding protein IGFBP-3 has recently been studied and found to increase with chondrocyte age paralleling an age-related decline in matrix synthesis activity. IGFBP-3 is actually over expressed and osteoarthritic cartilage with resultant disturbances in metabolic activity and subsequent matrix degeneration. These observations may indicate that IGFBP-3 plays a crucial role and regulating matrix synthesis and cartilage. Cartilage damage control mechanisms may fail because of age-related changes in IGFBP-3 expression or distribution. It is likely that the chondrocyte and the area of territorial matrix play important roles and the cartilage damage control by interfering with a chondrocytes ability to respond to IGF-1 [32].

\section{Biologic repair of damaged cartilage}

There are a multitude of biologic surgical techniques to address isolated traumatic articular cartilage defects. These techniques offer a 70 percent good to excellent result in restoration of function and reduction in pain (Figure 2). 


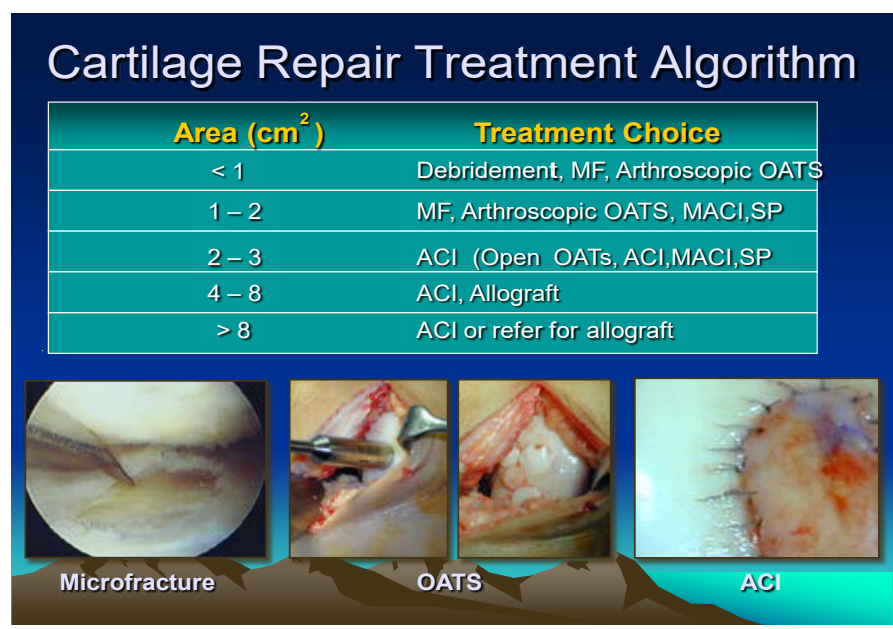

Figure 2. Treatment algorithm for cartilage repair

\section{Marrow stimulation}

Early research has been directed at filling articular defects with tissue that approximates articular cartilage by stimulating the repair tissue from the marrow. Stem cells are capable of developing into a multitude of tissues. Bone, muscle, fat, tendon, and cartilage have all been obtained from these multipotent cells. A stem cell population capable of differentiating into cells that can produce cartilage are obtainable from the bone marrow. In human studies, the fraction of stem cells that retained the ability to develop various types of tissue declines radically from 1 in 20,000 cells and juvenile human still only 1 in 4,000,000 during late adult life [33-37].

Microfracture of the subchondral bone is felt to deliver stem cells from the bone to the articular surface resulting in nechondrogenesis $[38,39]$. The majority of studies are based on human clinical results from microfracture (Figure 3).

The origin and differentiation of cells in the repair of $3 \mathrm{~mm}$ diameter cylindrical full-thickness articular cartilage and bone defects was studied by Shapiro et al. in New Zealand White rabbits [40]. In the first few days, fibrinous arcades were established and the defects within the clot from surface edge to surface edge. At 10 days, Safranin-O staining revealed evidence of GAG-containing extracellular matrix. By 14 days, a type of cartilage like tissue was present immediately beneath the surface of the fibrinous arcades. This substance was densely populated with flattened fibrocartilaginous cells. By 3 weeks, the sites of almost all the defects had a well demarcated layer of cartilage-like tissue. Autoradiography after labeling with ${ }^{3} \mathrm{H}$ - thymidine and ${ }^{3} \mathrm{H}$ - cytidine showed that chondrocytes from the adjacent native cartilage did not participate in the repopulation of the defect. The cartilage and just repair seemed to be mediated by the proliferation and differentiation of mesenchymal cells from the bone marrow. Interestingly, the radioisotope label which was taken up by undifferentiated mesenchymal cells appeared not only in the new chondrocytes but also in fibroblasts and osteoblast. Early traces of degeneration of the new cartilage matrix were seen in many of the defects by 12 weeks with the prevalence and severity of the degeneration increasing at 24 to 48 weeks. Polarized light microscopy showed that the newly synthesize matrix had failed to integrate with the native cartilage adjacent to the drilled hole. It was hypothesized that the lack of integration allowed motion of the repair substance with the resultant early degeneration.

It has been shown that periosteal and bone marrow drive cells can produce similar pattern of differentiation intra-articular cartilage in
New Zealand White Rabbits [41]. Trypsin was used to digestive free periosteal and bone marrow drive cells which were then implanted into a type I cartilage gel implanted into the site. Gel only and control rabbits did not have the same repair of cartilage and subchondral bone full within the $3 \mathrm{~mm}$ defects as the cell impregnated gel defects. The cell impregnated gels had good reparative tissue that resembles Hylan cartilage. This Hylan like cartilage thinned out over a period of 24 weeks [41] (Figure 4).

\section{Osteochondral grafts}

The successful transplantation of articular cartilage that is capable of restoring joint function, providing pain relief, and giving long-term reproducible excellent outcomes has been the holy grail of cartilage repair. Lexer attempted substitution of whole joints as far back as 1908 by 1925 was noted that even though whole joint transportation her initial good clinical results, the one that did not fail went on to frank degeneration changes in the cartilage [42,43]. It was not until the early 1950 s with a canine animal model was used to study morphologic and histologic differences between autografts and allograft after transplantation. They must remain viable and capable of continued production of normal matrix. The matrix must remain mechanically competent without degeneration or substitution to a fibrocartilage. The bony portion of the graft must integrate with a form a mechanically sound union with the host recipient site. Mechanical instability seems to indicate the development of an immune response [44].

In the late 1970s and early 1980s, there were a number of studies that examined various aspects of cartilage transplantation and animals to delineate the optimal conditions of transplantation. Autograft and allograft osteochondral transplantation were studied using gross

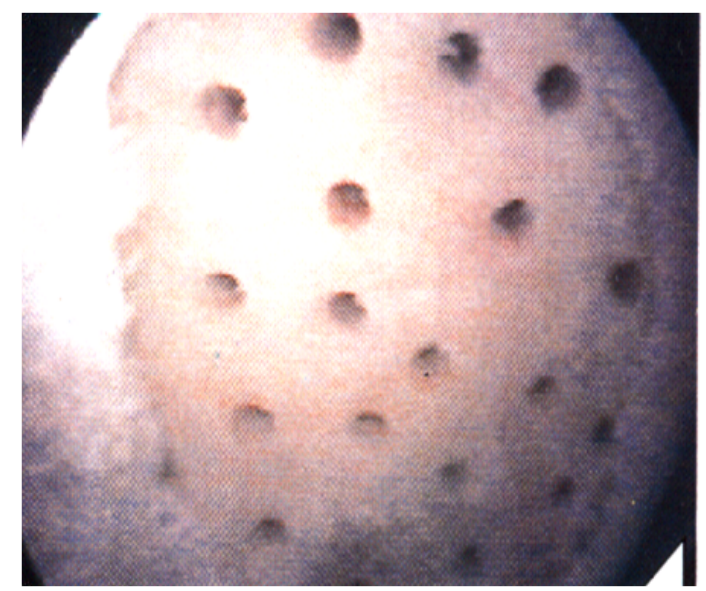

Figure 3. Microfracture of exposed bone

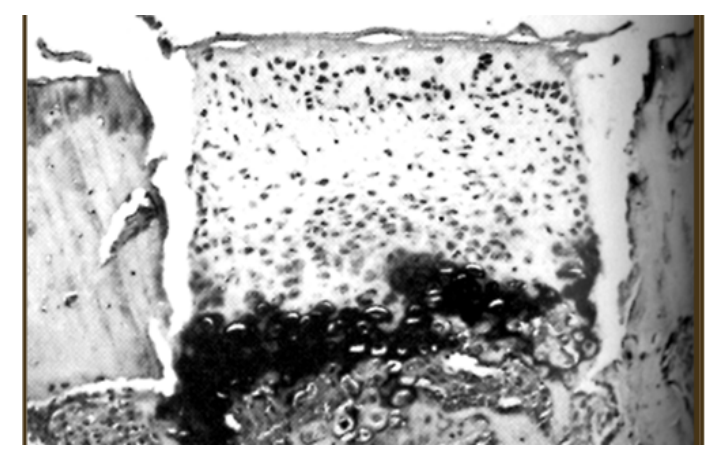

Figure 4. Histologic view of microfracture 
observation, radiology, histology, histochemistry, and biochemistry. Lane and Brighton [45] examined joint resurfacing in the New Zealand White rabbit using autologous transplanted femoral condyles. The lateral femoral condyle was completely excised and then fixed back into its original position with a straight Keith needle. Subsequent examination revealed that an $80 \%$ of these cases the cartilage surface appeared normal. At 1 year, histologic examination show that the thickness of the cartilage had been preserved with the exception of a few areas of localized thinning of the cartilage. Biochemical analysis of the harvested implants revealed a DNA, hydroxproline content, and S04 incorporation were equal to that of the non-harvested portions of the joint or to sham operated intact condyles.

Lipton et al. used a similar protocol to study follow transplantation of osteochondral grafts [46]. Osteochondral femoral allografts were performed and male adult New Zealand weight rabbits. Paired arthrotomies were performed simultaneously in different rabbits. The left lateral femoral condyles were osteomized and an osteochondral graft was harvested with $5 \mathrm{~mm}$ of subchondral bone. Care was taken to not transplant any soft tissue. The grafts were then switched and translated from 1 rapid to the other and fixed with small $\mathrm{K}$ wires. The rabbits were allowed full weight bearing without immobilization. The condyles were then harvested at 3, 6, in 18 months. Physical examination of the joints before harvest revealed no swelling, inflammation, or instability of any of the knee joints. However, gross inspection of the joints at necropsy revealed that one third of the joints had sustained advanced cartilaginous degeneration with fraying and even absent articular cartilage leading to eburnation of the bone. Two thirds of the joints appeared normal. Arthritic degeneration was noted to correlate with the joints that had not maintained an anatomic reduction after allograft transfer. Histologic analysis of the allografts that had maintained anatomic reduction revealed no differences when compared with cartilage from the undisturbed contralateral joint. Biochemical testing performed on the anatomically reduced allografts at 3,6 , in 18 months after transplantation showed no statistical difference with respect to protein, collagen, hexosamin, or hydroxproline content. The incorporation of SO4 was studied both in vivo and in vitro and no statistically significant differences were noted between the experimental and control condyles indicating acute metabolism was occurring. Biomechanical testing of the harvested specimens that had retained anatomic reduction revealed that there was no statistically significant difference in percent creep, instantaneous shear modulus, or relaxed shear modulus between allograft and control cartilage. The allografts that did fail seemed to do so because of mechanical problems of fixation and no graft rejection [46].

In 1980, De Nubile et al. published data on aloe transplantation of preserved and fresh articular cartilage using an osteochondral plug model [47]. It was thought the plug geometry would be mechanically stable construct and that the grafts would not undergo premature degeneration. Osteochondral plugs measuring 3-5 $\mathrm{mm}$ in diameter were obtained with a remnant thickness of $1 \mathrm{~mm}$ of subchondral bone from the New Zealand weight rabbits. A recipient rabbit was prepared and the donor plug was press-fit into place. No additional fixation besides the press-fit was used for graft stabilization. The allografts transplanted in this matter were examined at 3, 6, in 18 months. Gross examination revealed that there was almost complete preservation of cartilage thickness in the majority of the specimens the edge his were well united with no clefts. Safranin - O staining revealed that the protocol like a content of the allograft was preserved. A few of the plugs failed to unite to the recipient host bone and there was a proliferation of fibrous material around the plug. Some of the plugs also appeared to have subsided or were left protruding. The cases in which there was evidence of mechanical instability or subsidence or protrusion resulted in poor preservation of the cartilage matrix. Of special note, a few of the specimen samples appeared to have developed an immediate neurologic reaction that was interpreted as rejection. There were areas around these plugs that contained large numbers of monocytic and plasma inflammatory cells. The office felt that overall good to excellent results had been achieved in $60 \%$ of the specimens. Those plugs or mechanically unstable seem to manifest this inflammatory response.

\section{Autograft mosaicplasty}

In 1991, Lazlo Hangody et al., conceived of a method to use small cylindrical bottle obvious osteochondral plugs for the treatment of focal chondral and osteochondral defects of the femoral condyles and the knee $[48,49]$. He tested the concept of mosaicplasty osteochondral transplant and debridement of working dogs. The graft sizes ranged from 2.7 to $4.5 \mathrm{~mm}$. The peripheral margin of the distal femoral supracondylar ridge was selected as the donor site because of its the cartilage morphology and non-weight bearing location. At 4 weeks, the cancellous bone between the donor plugs and the recipient graft site had united. At 8 weeks, there was a seal between the recipient and the donor surface that was interpreted to be a fibrocartilage the produce matrix integration. The original donor sites filled with cancellous bone and fibrocartilage. This fibrocartilage was also firmly adherent to the surrounding cartilage. Histologic examination of the grafts revealed that the Highland morphology of both the chondrocytes in the cartilage matrix was maintained. In another study, the grafts were all $4.5 \mathrm{~mm}$ and 18 were on the non-weight bearing lateral side and 18 were on the weight bearing medial side. The lateral side fared better over a years' time and there was sustained good interplug fibrocartilage fill (hagody). On the basis of these results, the technique was then taken to the clinic and used on humans (Figures 5 and 6).

\section{Allograft}

It is useful to compare organ allografts from other parts of the body to understand the considerations for osteochondral allograft surgery. In the case of the heart transplant, the cells must remain alive for function and there is no tissue replacement from the recipient. The matrix is not replaced and it is maintained by the original organ cells. Tissue donor to host compatibility is important. In the case of bone

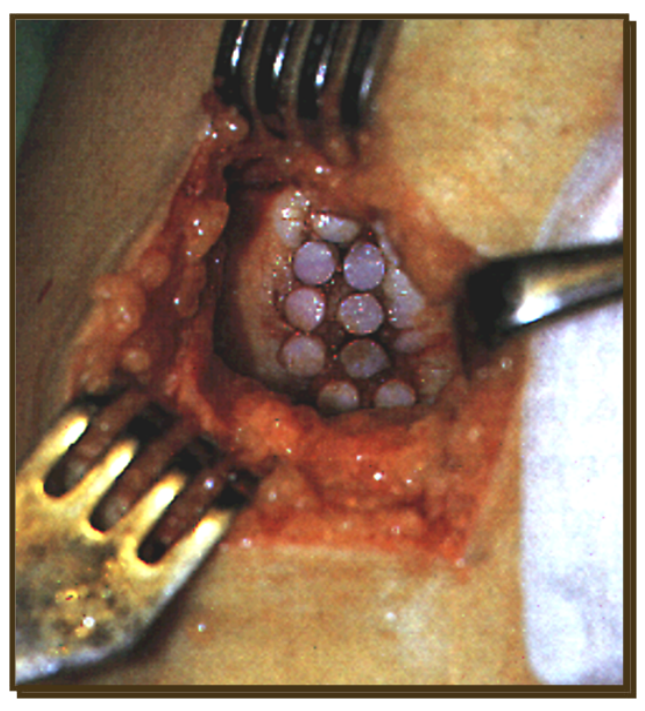

Figure 5. Mosaicplasty 


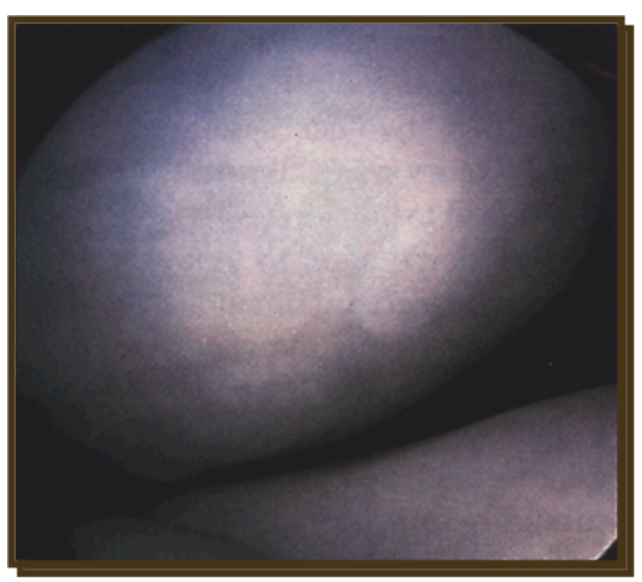

Figure 6. Repair tissue from microfracture

and cartilage transplantation, fresh or frozen bone graft is usually dead on transplantation unless there is good grafted vascular supply. Over time, dead bone is replaced by living bone. In the case of cortical bone this process is slow and may only involve a few millimeters of depth. Tissue donor to host compatibility is a minor issue unless marrow elements are present. Unfrozen articular cartilage has chondrocyte survival, no rejection, and no posterior graft cell repopulation (chimerism). Although the graft articular cartilage matrix seems to be maintained over years, there are studies of cartilage metabolism and allogenic osteochondral grafts that show a lower cell count and reduce metabolism. The bone is eventually replaced by host bone but the bone of the cartilage bone interface does not participate in this process [50]. Brighton et al., examined medicines of articular cartilage storage with the application of tissue culture techniques. Mechanical and histologic examination of the stored constructs was normal when compared with controls [51]. I performed another study in which the osteo-articular constructs were stored for 30 days, was again found that the biomechanical properties of the constructs were essentially normal when compared with controls. Histologic examination show that there was only minor swelling of the chondrocytes and that the histochemistry appeared to be normal. Incorporation of SO4 seem to be increased when compared with fresh control samples but there appeared to be normal amounts of hydroxproline and hexosamine. Animal studies were then undertaken with transplantation of the stored osteoarticular allograft plugs into New Zealand White rabbits. The results were evaluated at 12 months after transplantation with gross examination as well as mechanical and biochemical testing. Over $70 \%$ of the transplanted osteoarticular grafts showed loss of cartilage thickness, irregularity, and fibrillation. Histologically, several of the graft showed evidence of an immune reaction with large numbers of inflammatory cells and apparent graft necrosis. There was only $50 \%$ retention of proteoglycan content but hydroxyproline content was not significantly different from control values. Only $20 \%$ of the grafts appeared to have preserved matrix integrity. Gel filtration chromatography of sulfate- labeled macromolecules in guanidine HCL was used to index the quality of the proteoglycans synthesize by fresh and stored osteoarticular allograft plugs. A characterization of the proteoglycan eluted from the grafts revealed that the stored grafts had partially degraded molecules despite a normal staining with Safranin-O and normal SO4 content. This qualitative degeneration of cartilage cardio glycan was thought to resultant susceptibility to mechanical an immunologic failure. Amiel and Schacher have also looked at cartilage storage [52,53].
Osteochondral allografts can be of 3 types: Shell allograft, mosaicplasty, and large fragment osteochondral allograft. Fresh allograft replacement surgery has been performed for primary osteoarthritis, osteonecrosis, osteochondritis dissecans, and posterior medical defects. Procedures for protuberant fresh allograft material have been established by the American Association of tissue banks. Donors must be below 30 years of age which is not to maximize cartilage quality. The grafts are harvested under strict aseptic conditions and usually within 24 hours after death. The entire joint is harvested with joint capsule ligaments cartilage and metaphyseal bone being excised en bloc. Cultures are taken after harvest in the entire joint is immersed in lactated Ringer's solution with cefazolin and bacitracin antibiotics being included in the solution. After the container sealed off, it is stored at $4^{\circ} \mathrm{C}$. Histocompatibility markers are not obtained. Donor and recipient are matched for size and transplantation must take place in less than 1 week.

A biomechanical and biochemical study conducted by Jimenez and Brighton studied fresh frozen osteochondral allografts and rabbits [44]. The graft was stored for 30 days and tissue cultures conditions. They found that $70 \%$ to $75 \%$ of the sample did not appear normal and manifested early degenerative changes including fibrillation and loss of proteoglycan. By comparing cryopreservation techniques with fresh osteochondral allograft, it was found that cryopreservation resulted in less immunologic antigenicity but also marked degeneration of the cartilages matrix and chondrocyte viability. In 1985 study by Czitrom et al., found that chondrocyte viability and fresh osteochondral allograft ranged from $69 \%$ to $99 \%$ when assessed in culture media from biopsy specimens by S04 and 3H-cytidine auto radiography and grafts 1-6 years after implantation [54]. One six-year graft had only $37 \%$ chondrocyte viability but they were actively producing proteogylcans. Human chondrocytes in the cartilage of a fresh osteochondral graft can apparently survive prolonged periods of time. Oakshott et al., analyzed 18 cases of failed fresh allografts and found that the grafted bone had indeed died [55]. Twelve of the 18 grafts had viable cells at 13-92 months. Convrey et al., has also found allograft chondrocyte survival 8 years after implantation [56]. There seems to be a cell mediated immune response that is responsible for the allografted bone graft rejection. Langer et al. has demonstrated a positive lymphocytic migration test after graft transplantation. The allograft may actually soften with subsequent creeping substitution from the posterior tissue taking place over several years. Graft subsidence has actually been observed at 2-3 years status postindex surgery and is likely because of a delay in early revascularization as a result of the immune response and softened subchondral bone. Basic animal research has shown the importance of isolation of allogenic chondrocytes from post subchondral bone [57] (Figure 7).

Mohamed et al., followed 92 posttraumatic knee injuries who received fresh allograft reconstruction of a small osteochondral lesion of either the tibia or femur [58]. Failure was defined as less than 20 points of improvement on the knee assessment scoring system from hospital for special surgery, any revision procedure, or subsequent patient assessment that the knee was worse. There was clinical success and $75 \%$ at 5 years, $64 \%$ to 10 years and $63 \%$ at 14 years after implantation (Figures 8 and 9).

\section{Autogenous chondrocyte implantation}

Human chondrocytes have been cultured for autologous chondrocyte transplantation and human since 1987. Peterson et al., reported on successful treatment of focal patellar defects in a rabbit mode with the use of transplanted cultured autologous chondrocytes 


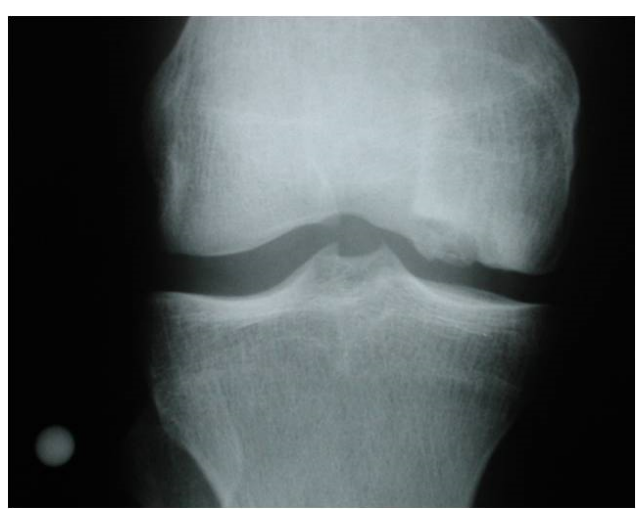

Figure 7. Damage cartilage as it appears on radiograph

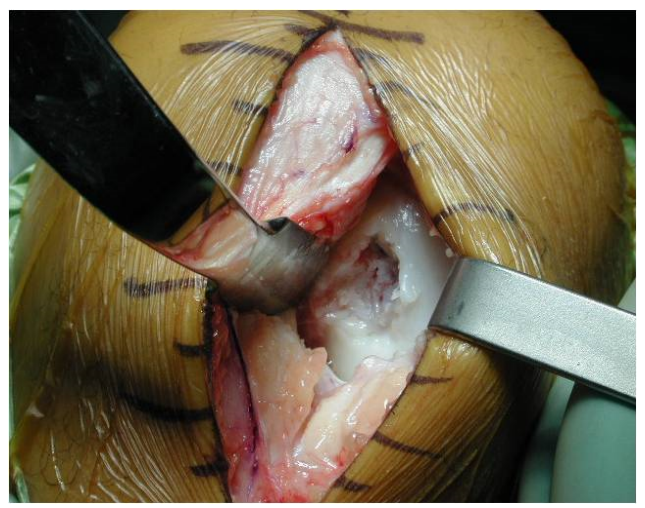

Figure 8. Damaged cartilage

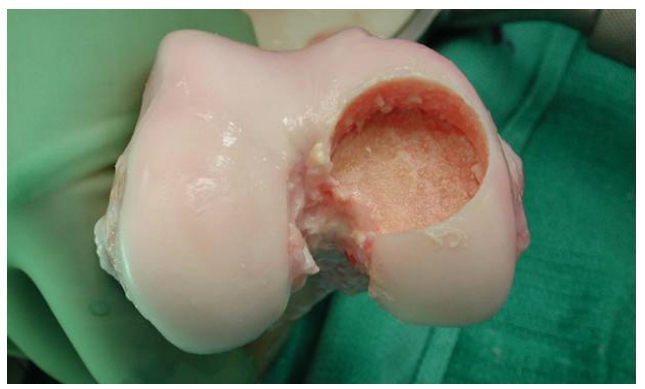

Figure 9. Allograft recipient site

[59]. The cultured chondrocytes were injected under a periosteal flap which was sutured over the patellar defect. Examination 1 year after transportation revealed that a cartilage-like tissue covered about $70 \%$ of the defects. In 1994, Britberg et al. [60] reported on the results of 23 patients treated with Autogenous Chondrocyte Implantation (ACI) with a 16-66-month follow-up [60]. Second look arthroscopy allowed clinical examination at 3 months. These examinations revealed that the transplants were level with the surrounding tissue and somewhat spongy when probed. A second arthroscopic examination was performed on a subset of these patients at 12-46 months and clinical examination revealed that the transplant had progressed through a maturation process and had firmed up. During the second arthroscopic procedure, biopsy specimens extending to the subchondral bone were taken from the central portion of the transplant. Histologic examination and biochemical staining of the transplant biopsies revealed that the transplant had an abundance of type II collagen similar to normal articular cartilage.
It has been theorized that because chondrocytes are encased by matrix that they lack the ability to migrate to the site of chondral injury and actively participate in a repair process $[61,62]$. And we'll studies have shown the partial-thickness chondral injuries can sometimes undergo repair by stem cell migration from adjacent synovial tissues. Full-thickness chondral lesions and adult humans have not shown the capacity to heal. Stem cell migration from the underlying subchondral bone with defect filling by fibrocartilage has been studied extensively and has produced variable results as to effectiveness. The resulting fibrocartilage repair tissue is predominantly fibrous in nature, with variable numbers of chondrocytes present. The tissue at a microscopic level seems unorganized and lacks the biochemical and viscoelastic characteristics of normal Hylan cartilage [63]. The implanted chondrocytes, when studied with radioisotope labeling, seemed to physically adhere to the wound bed and significantly contribute to the repair tissue. Breinan et al., created $4 \mathrm{~mm}$ defects in the trochlear groove and 3 randomized groups of dogs [64]. One group had an empty defect, one group had periosteum sewn over the defect, and a throat group had autogenous chondrocyte transplantation with periosteum. Histomorphometric analysis at 12 and 18 months revealed the defect fill was $36 \%$ to $76 \%$, Hylan-like cartilage was $10 \%$ to $23 \%$, and integration with surrounding cartilage was $16 \%$ to $32 \%$ with no significant difference between 3 groups. Peterson et al., performed arthroscopic second looks on 65 patients who had undergone ACI during a 2 to 9 year outcome study [65]. Quality of the repair tissue was assessed as to defect fill, integration with the surrounding cartilage, and surface mechanical characteristics. Biopsy specimens from the central portion of the grafted site were also obtained. Macroscopic assessment of the repair tissue revealed that the implants slowly matured over the course of the year. Arthroscopy performed in the first 2-3 months showed a repair construct that was typically soft and had a wavelike pattern of graft movement when probed. By 12 months the repair tissue was almost as firm as the adjacent cartilage. Histopathologic analysis was performed on 37 biopsy specimens. Three pathologists who had been blinded to treatment outcomes were asked to evaluate the tissue samples. Most of the specimens were thought to have a homogenous matrix with low cellularity, with rounded chondrocytes encased in typical lacunae, which was consistent with hyaline cartilage. The size, shape, and cell features were characteristic of hyaline cartilage. Immunohistochemical staining was positive for type II cartilage and normal proteoglycan content and all specimens that had a Hylanlike appearance. There was a positive correlation between Hylan like Reconstruction of the defect and clinical outcome differences on histologic examination wore a greater number of chondrocytes with a more random distribution of cell colonies and absence of columnar organization. As a periosteal envelope was created to facilitate the constructs application, it should be noted that in some biopsy specimen the most superficial layer was composed of remnant fibrous sites which were likely incorporated from the periosteum. The periosteum seems to incorporate into the repair tissue through metaplasia and is mechanically debrided from the surface of the construct during the first 3-5 months. Contaminating cells may not come from just the periosteal envelope. Cells from the synovium and bone may also contribute biologically to the chondrocyte culture medium. Lovstedt $e t$ al., found that by using a combination of primers for ostial keelson and collagen types $2 \mathrm{~A}+\mathrm{B}$, they were able to positively identify chondrocytes before cell culturing [66]. The culturing of chondrocytes for ACI has been time-dependent. Cell culture methods usually required that the cell isolation take place within 6 hours after surgery, followed by augmentation and implantation in 14-21 days. Leela and Bentley examined the capability of chondrocytes from damaged articular 
cartilage to function and ACI [67]. In an effort to avoid iatrogenic damage to the knee, the debrided cartilage in the perilesional area was collected and enzymatically digested and processed according to standard protocol. Histologic and immunohistochemical analysis was carried out as well as assays for DNA and GAGs. The chondrocytes obtained from the debrided cartilage lesion were equivalent to those obtained from harvested healthy cartilage areas. Sufficient cell numbers for implantation were achieved for all patients. The only difference was that the patients who had cartilage scavenged from large degenerative lesions required significantly longer times in culture to obtain the required number of cells.

Matrix associated autologous under site transportation/ implantation is a new operation that uses chondrocytes seated into engineered matrix. it is using the treatment of localized full-thickness cartilage defects. Behrensa et al., published in knee on 5 year follow-up of 30 patient's treated with matrix associated autologous chondrocyte transplantation/implantation [68]. Four different scoring systems including the Meyer score, Tegner-Lyshlom activity score, LysholmGillquist score, and the international cartilage repair Society score were used in the conjunction with a subset of patients who underwent biopsy. 5 years after implantation, $72 \%$ of patients rated the function of their knee much better than before (Figures 10 and 11).

\section{Autologous chondrocyte implantation}

The innovation of cell-based therapies to treat articular cartilage defects began with an autologous chondrocyte implantation (ACI) technique first described over 25 years ago $[69,70]$. Early generations of ACI utilized an injectable suspension of cultured chondrocytes beneath a secured manufactured biologic cover over the defect site [69,70]. First generation of ACI used a porcine periosteal cover (ACI-P) which was replaced by a collagen type I/III cover in the second generation ACI-C both of which were secured with sutures; the collagen cover was proven to have lower instances of post-operative hypertrophy compared to periosteal covers $[69,70]$. Third generation of cell-based regenerative therapy for treatment of full-thickness cartilage defects is referred to as maxtrix-induced autoloug chondrocyte implantation (MACI) which adapted the second generation collage type I/III membrane into a bilayer membrane "seeded" with autologous chondrocytes and secured with fibrin glue [69-74]. MACI is a two-stage procedure including harvesting of chondrocytes for graft preparation then transplant/implantation of chondrocyte matrix graft approximately 4-6 weeks later. Chondrocytes are isolated and cultured in a mono layer. However, chondrocytes dedifferentiate in monocultures and restoration of their chondrocytic phenotype is critical to cartilage graft success (Figures 12 and 13) [73].

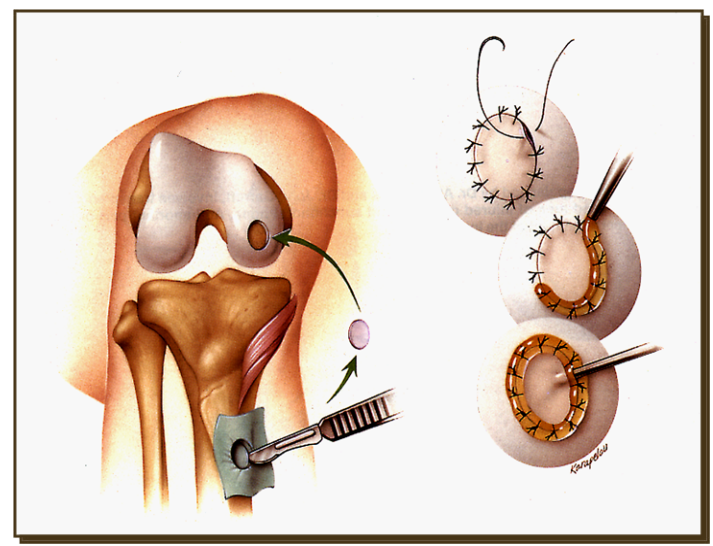

Figure 10. ACI Surgical procedure

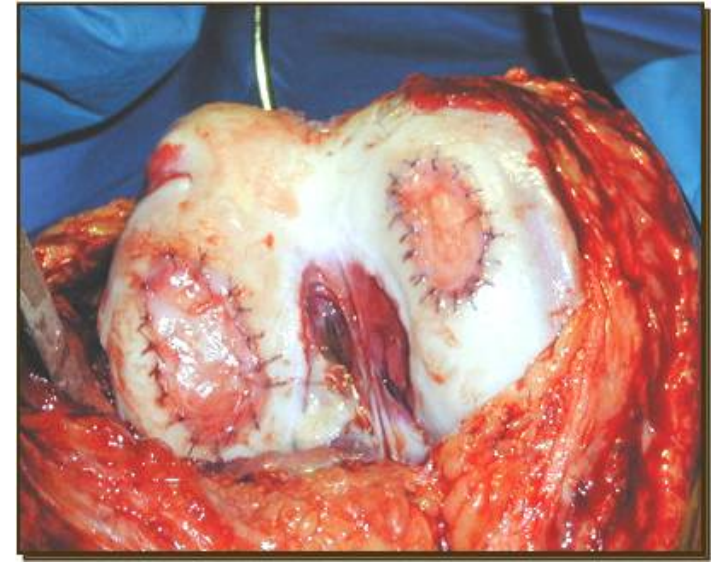

Figure 11. Status post ACI implantation

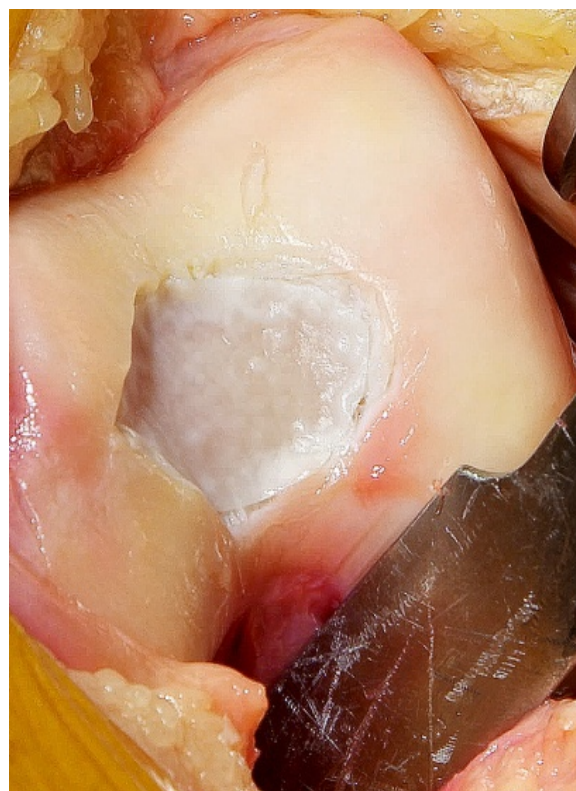

Figure 12. Damaged cartilage

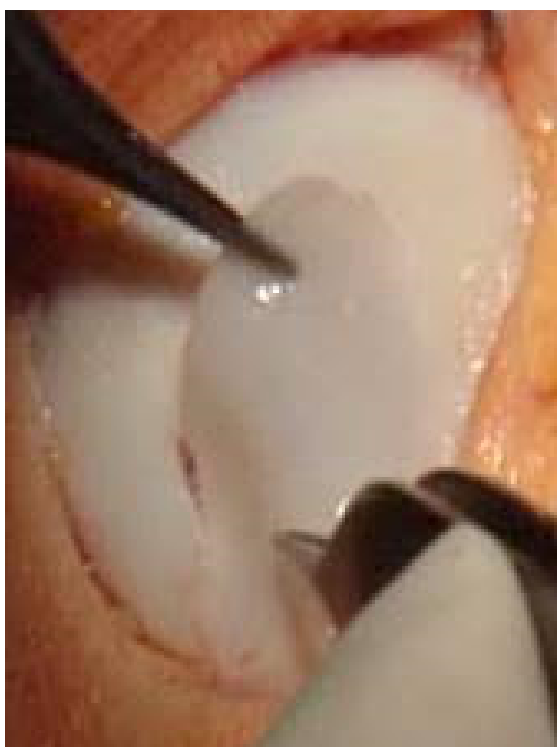

Figure 13. Allograft implant 


\section{Subchondroplasty}

Bone Marrow Lesions (BML) are associated with mechanical or inflammatory injury to subchondral bone and are identifiable by a distinct MRI water signal. Best visualized on T2 fat suppressed MR imaging, BML are recognized as hyperdense homeogenetic water signals of subchondral bone without sharp margins or respect for anatomical boundaries. Although most commonly occurring in loadbearing regions, BML location has also been correlated with entheses in inflammatory cases. In prior literature, BMLs were referred as bone marrow edema due to their characteristic MRI water signal. The term bone marrow lesion has been adopted after histological analysis revealed BML lack edematous changes; BML histology has been described as fibrosis lymphocytic infiltrates and increased vascularization of subchondral bone. The size of BML have proven to be clinically significant and positively correlates with disease progression and pain [75]. It is well-known that knee joint space narrowing appreciated on plain $\mathrm{x}$-rays inconsistently correlate to the severity of symptoms reported by patients. However, the presence of BML visualized on MRI strongly correlated with severity of reported pain. Bone marrow edema is postulated to contribute to the progression of cartilage defect/ arthropathy because the compromised bone fails to distribute force laterally through cartilage and the softer tissues receives focal, vertical forces. Chronic BML associated with OA represent a new target for treatment though, adapted, but familiar techniques of internal fixation and bone stimulation use to treat non-healing fractures. The role of subchondroplasty is to deliver a bone substitute to the subchondral BML to restore structural support and facilitate bony healing [76]. BML associated with OA are hypothesis to develop through an "inside-out" mechanism; whereby microfractures elicit localized proinflammatory cytokines and vascoactive agents in bone marrow. In contrast to an "outside-in" mechanism characteristic of inflammatory arthropathies such as RA or psoriasis whereby inflammatory cells enter into the bone marrow [75].

In 2007 the minimally invasive orthobiologic procedure, Subchondroplasty (SCP), was developed and has been utilized to treat chronic and acute Bone Marrow Lesions (BML) of the subchondral bone. Under fluoroscopic guidance a flowable bone substitute is injected directly into the BML until a darkened blush is seen to mimic the BML pattern under fluoroscopy and is often combined with additional arthroscopic and extra-articular procedures [77]. The properties of the injectable CaP are important to consider. This synthetic bone substitute must be injectable and flowable but solidify via endothermic reaction as to avoid surrounding cell death. As a solid the $\mathrm{CaP}$ needs have similar structural properties to native cancellous bone to minimize inflammatory response. Lastly, the bone substitute must be biologically reabsorbable to allow for bony healing [78]. This scaffolding-like bone substitute facilitates the remodeling capabilities of local osteoclasts or osteoblasts [79]. For patients with notable knee misalignment, greater than 8 degrees of varus or valgus malalignment, it is strongly recommended that SCP is paired with joint realignment procedures. SCP have frequently been documented to be paired with arthroscopic procedures as needed after intra-articular pathologies are assessed. Thus far there have been minimal complications associated with SCP. A few patients have experienced persistent postoperative pain due to bone substitute hardening in surrounding soft tissue. Patients who later elected to proceed to definitive treatment of TKA did not experience any complications due to synthetic bone substitute [78]. The subchondroplasty procedures has primarily been described to treat BML of the tibiofemoral articulation. More recent studies have introduced the SCP procedure for treatment of BML of the patellofemoral articulation. SCP have been most successful in treating $\mathrm{BML}$ of load-bearing regions of the knee in contrast to treating
BML at entheses [79]. While subchondroplasty studies have revealed promising results for this procedure, the limits to which this procedure can provide patients with pain relief and improved function are still being determined. Chatterjuu et al., provided evidence that injectable $\mathrm{CaP}$ into subchondral BML did not reliably provide pain relief and/ or improved function to patients with advanced knee OA [80]. This study demonstrates that $31.8 \%$ of patients, out of 22 patient study group, with grade III or IV cartilage defects experienced a poor surgical outcome which was measured post-operatively with KOOS, Tegner and Lysholm scores [80]. The 6-year prospective nonrandomized study of subchondroplasty effectiveness published by Cohen and Skarkey reported durable improvement of pain scores and symptom/function scores from patients status post knee subchondroplasty via arthroscopy [77]. Of note, patients with grade IV tricompartmental knee OA were excluded from this study group. After undergoing SCP, 70\% of the included patients who were originally consulted for total knee arthroplasty did not proceed to this definitive treatment option within the study period. Interestingly, those patients who proceeded onto TKA did so within the first year after SCP. The advantages of subchondroplasty are notable for its minimally invasive approach that preserves native joint space and provides reliable pain relief in the short and long term with a shorter postoperative recovery compared to TKA [77].

\section{Osteotomy}

Osteotomy of the tibia or femur may be performed to improve the mechanical axis of involved knee joints (Figure 14-16)

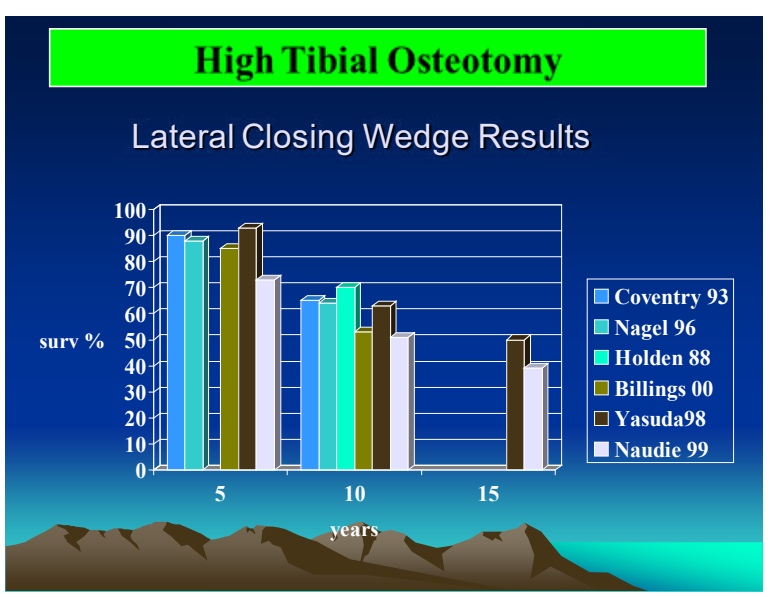

Figure 14. High Tibal Osteotomy

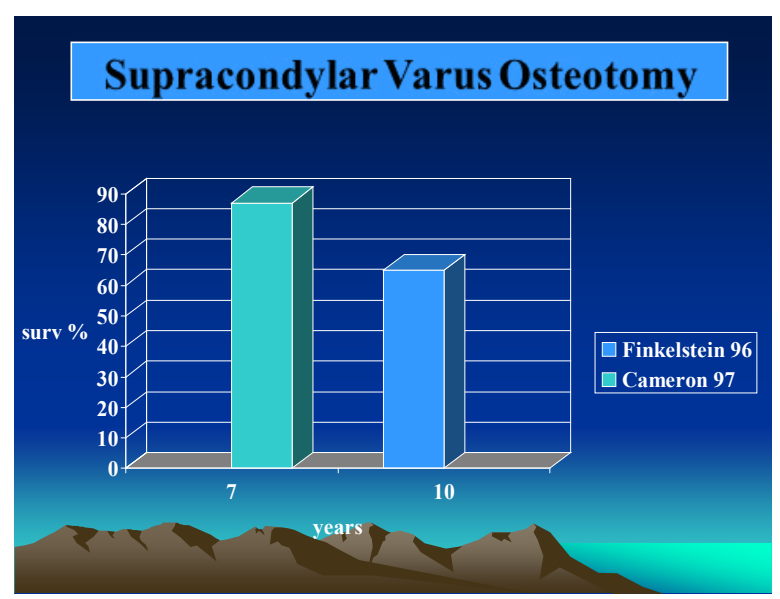

Figure 15. Supracondylar varus osteotomy 


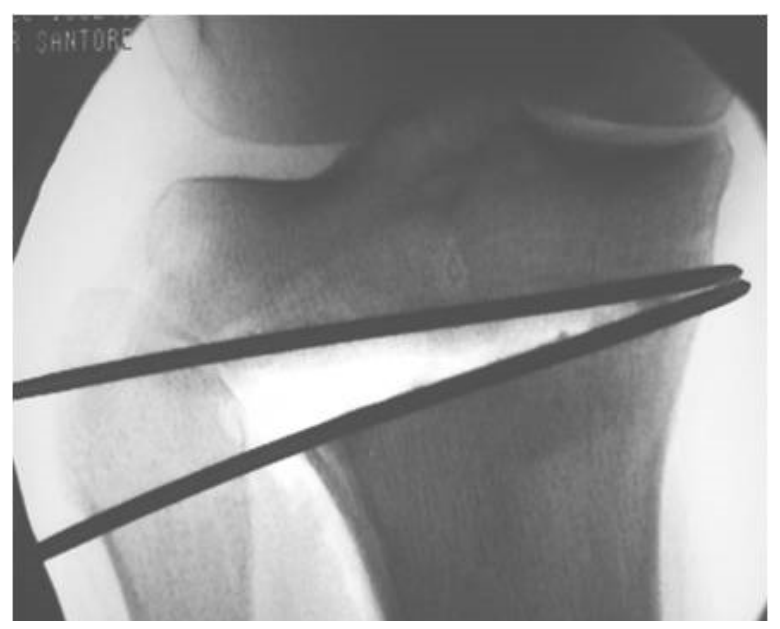

Figure 16. High tibial osteotomy

\section{Summary}

Orthopedic surgeons involved and cartilage replacement and preservation surgery must be aware of many outstanding basic biologic issues they face. Articular cartilage and its adjoining bony surface is a remarkable organ that demands respect for its biology and require attention to the many mechanical and biochemical details that should be considered for surgical planning. It is also incumbent on the surgeon to keep abreast of changes in the biologic literature and evidence pain clinical literature that will continually alter their practice. Although cartilage has a highly stable component to its matrix, it is capable of recovery and prolonged life given the proper environment.

\section{References}

1. Goldring MB, Goldring SR (2007) Osteoarthritis. J Cell Physiol 213: 626-634. [Crossref]

2. Moreland LW (2003) Intra-articular hyaluronan (hyaluronic acid) and hylans for the treatment of osteoarthritis: mechanism of action. Arthritis Res Ther 5: 54-67. [Crossref]

3. Wesseling J, Welsing PM, Bierma-Zeinstra SM, Dekker J, Gorter KJ, et al. (2013) Impact to self-reported comorbidity on physical and mental health status in early symptomatic osteoarthritis: The CHECK (Cohort hip and Cohort knee) study. Rheumatology (Oxford) 52: 180-188. [Crossref]

4. Hagans MP, Cederberg H, Mikkola I, et al. (2012) Reduction and metabolic syndrome, obese young Mammon and associated with exercise-induced body composition changes during military service. Diabetes Res Clin Pract 98: 312-319.

5. Costa FF, Montenegro VB, Lopes TJ, Costa EC (2011) Combination of risk factors for metabolic syndrome in the military personnel of the Brazilian Navy. Arq Bras Cardiol 97: 485-492. [Crossref]

6. Bay-Jensen AC, Hoegh-Madsen S, Dam E, Henriksen K, Sondergaard BC, et al. (2010) Which elements are involved in reversible and irreversible cartilage degeneration in osteoarthritis? Rheumatol Int 30: 435-442. [Crossref]

7. Goldring MB, Otero M (2011) Inflammation in osteoarthritis. Curr Opin Rheumatol 23: 471-478. [Crossref]

8. Maly MR (2008) Abnormal and cumulative loading in knee osteoarthritis. Curr Opin Rheumatol 20: 547-552. [Crossref]

9. Bagga H, Burkhardt D, Sambrook P, March L (2006) Longterm effects of intraarticular hyaluronan on synovial fluid in osteoarthritis of the knee. J Rheumatol 33: 946-950. [Crossref]

10. Caligaris M, Canal CE, Ahmad CS, Gardner TR, Ateshian GA (2009) Investigation of the frictional response of osteoarthritic human tibiofemoral joints and the potential beneficial tribological effect of healthy synovial fluid. Osteoarthritis cartilage 17 : 1327-1332. [Crossref]

11. Murphy L, Schwartz TA, Helmick CG, Renner JB, Tudor G, et al. (2008) Lifetime risk of symptomatic knee osteoarthritis. Arthritis Rheum 59: 1207-1213. [Crossref]
12. Rivera JC, Wenke JC, Buckwalter JA, Ficke JR, Johnson AE (2012) Posttraumatic osteoarthritis caused by Battlefield injuries: The primary source of disability and Warriors. J Am Acad Orthop Surg 20: 64-69. [Crossref]

13. Lohmander LS, Englund PM, Dahl LL, Roos EM (2007) The long-term consequence of anterior cruciate ligament and meniscus injuries: osteoarthritis. Am J Sports Med 35 1756-1769. [Crossref]

14. Hoshino Y, Fu FH, Irrgang JJ, Tashman S (2013) Can joint contact dynamics be restored by anterior cruciate ligament reconstruction? Clin Orthop Relat Res 471: 2924-31.

15. Jones JC, Burks R, Owens BD, Sturdivant RX, Svoboda SJ, et al. (2012) Incidence and risk factors associated with meniscal injuries among active-duty US military service members. J Athl Train 47: 67-73. [Crossref]

16. Ding L, Heying E, Nicholson N, Stroud NJ, Homandberg GA, et al (2010) Mechanical impact induces cartilage degeneration via mitogen activated protein kinases. Osteoarthritis cartilage 18: 1509-17. [Crossref]

17. Jaquet GJ (2013) EWI VIII: Sequelae of combat injuries. AAOS 2013; April. Available at www.AAOS.org $\backslash$ news $\backslash A A O S$ now $\backslash$ apr13 \clinical 2.asp; accessed 8 July 2013.

18. Goldberg VM, Goldberg L (2010) Intra-articular hyaluronans: the treatment of knee pain in osteoarthritis. J Pain Res 3: 51-56. [Crossref]

19. Genda E, Li G, Barrance PJ (1996) Functional analysis of hip joint contact pressure. Trans Orthop Res Soc 21: 416.

20. Kitaoka HB, Kura H, Luo ZP (1996) Contact features of the ankle joint. Trans Orthop Res Soc 21: 396.

21. Ameye L, Young MF (2002) Mice deficient in small leucine-rich pro, normal in vivo models for osteoporosis, osteoarthritis, Ehkers-Dabkins syndrome, muscular dystrophy and corneal disease. Glycobiology 12: 107R-116R. [Crossref]

22. Tsumura H, Miura H, Iwamoto Y (1998) Three-dimensional pressure distribution of the human hip joint comparison between normal hips and dysplastic hips. Fukuoka Igaku Zasshi 89: 109-118. [Crossref]

23. Walker PS, Erkman MJ (1975) The role of the menisci in force transmission across the knee. Clin Orthop Relat Res 184-192. [Crossref]

24. Brown TD, Shaw DT (1984) In vitro contact stress distribution on the femoral condyles. J Orthop Res 2: 190-199. [Crossref]

25. Buckwalter JA, Einhorn TA, Simon SR (2000) Orthopedic basic science. American cadmium orthopedic surgeon, Chicago.

26. Haskell VC, Sid Jara JW (1970) Physical properties N Polley disperse city of protoco I can from bovine nostril cartilage. J Biol Chem 245: 4920-4930.

27. Schinagl RM, Gurskis D, Chen AC, Sah RL (1997) Depth-dependent confined compression modulus of full-thickness bovine articular cartilage. J Orthop Res 15: 499-506. [Crossref]

28. Wong M, Wuethrich P. Buschmann MD, Eggli P, Hunziker E (1977) Chondrocyte Biosynthesis correlates with local tissue strain in static compressed adult articular cartilage. J Orthop Res 15:189-196. [Crossref]

29. Cochran GVB (1982) A Primer of Orthopedic Biomechanics. New York: Churchill Livingston, pp. 413. [Crossref]

30. Dye SF (1996) The knee as a biologic transmission with an envelope of function: a theory. Clin Orthop Relat Res 10-18. [Crossref]

31. Goldenberg VM, Kuettner KE. Osteoarthritic disorders. Chicago: American Academy orthopedic surgeons; 1995: xxii-xxiii

32. Martin JA, Scherb MB, Lembke LA, Buckwalter JA (2000) Damage control mechanisms in articular cartilage: the role of the insulin-like growth factor I axis. Iowa Orthop J 20: 1-10. [Crossref]

33. Martin JA, Scherb MB, Lembke LA, Buckwalter JA (2000) Damage control mechanisms in articular cartilage: the role of the insulin-like growth factor I axis. Iowa Orthop J 20: 1-10. [Crossref]

34. Convery FR, Akeson WH, Keown GH (1972) The repair of large osteochondral defects An experimental study in horses. Clin Orthop Relat Res 82: 253-262. [Crossref]

35. Fuller JA, Ghadially FN (1972) Ultrastructural observations on surgically produced partial thickness defects in articular cartilage. Clinc Orthop 86: 193-205. [Crossref]

36. Caplan AI (1991) Mesenchymal stem cells. J Orthop Res 9: 641-650. [Crossref]

37. Rodrigo JJ, Steadman JR, Sillman JF (1994) Improvement of full thickiness chondral defect healing in the human after debridement and microfracture using continuous passive motion. Am J Knee Surg 7: 109-116. 
38. Steadman JR, Rodkey WG, Singleton SB (1997) Microfracture technique and clinical results. Oper Tech Orthop 7: 300-304.

39. Salter RB, Simmonds DF, Malcolm BW, Rumble EJ, MacMichael D, et al. (1980) The biological effect of continuous passive motion on the healing of full-thickness defects in articular cartilage. An experimental investigation in the rabbit. J Bone Joint Surg Am 62: 1232-1251. [Crossref]

40. Shapiro F, Kiode S, Glimcher MJ (1994) Cell origin and differentiation in repair of fullthickness degevys of articular cartilage. J Bone Joint Surg 74: 523-533. [Crossref]

41. Wakitani S, Goto T, Pineda SJ, et al. (1994) Mesenchymal cell based repair of larger, full thickeness defects of articular cartilage. J bone Joint Surg 76: 579-592. [Crossref]

42. Lexer EL (1925) Joint transplantation and arthroplasty. Urg Gynecol Obstet 40: 782.

43. Lexer EL (1908) Substiution of whole or half joints from freshly amputated extremities by free plastic operation. Surg Gynecol Obstet 6: 601 .

44. Jimenez SA, Brighton CT (1983) Experimental studies on the fate of transplanted articular cartilage. In: Friedlander GE, Mankin HJ, Sell KW (eds.) Osteochondral Allografts, banking and clinical applications. Boston: Brown, 73-79.

45. Lane JM, Brighton CT (1977) Joint resurfacing in the rabbit using an autologous osteochondral graft: a biochemical and metabolic study of cartilage viability. $J$ Bone Joint Surg 59: 218

46. Lipton MA (1978) Allotransplantation: a historical, biochemical, and biomechanical study. Trans Orthop Res $\operatorname{Soc}$ 3: 12.

47. De Nubile NA (1980) Allotransplantation of preserved and fresh articular cartilage in an osteochondral plug model. Trans Orthop Red Soc 5: 74.

48. Hangody L, Kisk G, Karpati Z (1992) Autogenous osteochondral graft technique for replacing knee cartilage defects in dogs. Int Orthop 5: 175-181.

49. Hangody L, Kisk G, Karpati Z (1997) Autogenous osteochondral graft technique for replacing knee cartilage defects in dogs. Int Orthop 5: 175-181.

50. Nelson FR (1992) Chondrocyte engineering: in search of articular cartilage. MUSC Orthop J 2: 26-31. [Crossref]

51. Brighton CT, Shadle CA, Jimenez SA, Irwin JT, Lane JM, et al. (1979) Articular cartilage preservation and storage I. Application of tissue culture techniques to the storage of viable articular cartilage. Arthritis Rheum 22: 1093-1101. [Crossref]

52. Oates KM, Chen AC, Young EP, Kwan MK, Amiel D, et al. (1995) Effect of tissue culture storage on the in vivo survival of canine osteochondral allografts. J Orthop Res 13: 562-569. [Crossref]

53. Stevenson S, Dannucci GA, Shrkey NA, Pool RR (1989) The fate of articular cartilage after transplantation of freash and cryopreserved tissue-antigen-matched and mismatched osteochondral allografts in dogs. J Bone Joint Surg 71: 1297-1307. [Crossref]

54. Czitrom AA, Keating S, Gross A (1990) The viability of articular cartilage in fresh osteochondral allografts after clinical transplantation. J Bone Joint Surg 72: 574-581. [Crossref]

55. Oakeshott RD, Farine I, Pritzker KP, Langer F, Gross AE (1988) A clinical and histologic analysis of failed fresh osteochondral allografts. Clin Orthop Relat Res 283294. [Crossref]

56. Convery FR, Akeson WH, Amiel D, Meyers MH, Monosov A (1996) Long-term survival of chondrocytes in an osteochondral articular cartilage allograft. A case report. J Bone Joint Surg Am 78: 1082-1088. [Crossref]

57. Moskalewski S, Hyc A, Osiecka-Iwan A (2002) Immune response by host after allogeneic chondrocyte transplant to the cartilage. Microsc Res Tech 58: 3-13. [Crossref]

58. Mohamed MN, Beaver RJ, Gross AE (1992) The long-term success of fresh, small fragment osteochondral allografts used for intra-articular post-traumatic defects in the knee joint. Orthopaedics 15: 1191-1199. [Crossref]

59. Peterson L, Menche D, Grande D (1984) Chondrocytes transplantation: an experimental model in the rabbit. Trans Ortho Res Soc 18: 218

60. Brittberg M, Lindahl A, Nilsson A, Ohlsson C, Isaksson O, et al. (1994) Treatment of deep cartilage defects in the knee with autologous chondrocyte transplantation. $N$ Engl J Med 331: 889-895.
61. Hirotani H, Ito T (1975) Chondrocyte mitosis in the articular cartilage of femoral heads with various diseases. Acta Orthop Scand 46: 979-986. [Crossref]

62. Rothwell AG, Bentley G (1973) Chondrocyte multiplication in osteoarthritic articular cartilage. J Bone Joint Surg Br 55: 588-594. [Crossref]

63. Grande DA, Pitman MI, Peterson L, Menche D, Klein M (1989) The repair of experimentally produced defects in rabbit articular cartilage by autologous chondrocyte transplantation. J Orthop Res 7: 208-218. [Crossref]

64. Breinan HA, Minas T, Hsu HP, Nehrer S, Sledge CB, et al. (1997) Effect of cultured autologous chondrocytes on repair of chondral defects on a canine model. $J$ Bone Joint Surg 79: 1439-1451. [Crossref]

65. Peterson L, Minas T, Brittberg M, Nilsson A, Sjögren-Jansson E, et al. (2000) Two- to 9-year outcome after autologous chondrocyte transplantation of the knee. Clin Orthop Relat Res 212-234. [Crossref]

66. Lovstedt K, Thornemo M, Lindahl A (2002) Identification of Contaminating Cells from Biopsies Used for Articular Cartilage Repair. Toronto: International Cartilage Repair Society, 73.

67. Leela CB, Bentley G (2002) A novel Source of Cells for Autologous Chondrocyte Transplantation in the Adult Knee. Toronto: International Cartilage Repair Society, 54.

68. Behrens P, Bitter T, Kurz B, Russlies M (2006) Matrix-associated autologous chondrocyte transplantation/implantation (MACT/MACI) - 5 year follow up. Knee 13: 194-202. [Crossref]

69. Bartlett W, Skinner JA, Gooding CR, Carrington RWJ, Flanagan AM, et al. (2005) Autologous chondrocyte implantation versus matrix-induced autologous chondrocyte implantation for osteochondral defect of theknee. J Bone Joint Surg Br 87-B: 640-645. [Crossref]

70. Basad E, Wissing FR, Fehrenbach P, Rickert M, Steinmeye J, et al. (2015) Matrixinduced autologous chondrocyte implantation (MACI) in the knee: clinical outcome and challenges. Knee Surg Traumatol Arthrosc 23: 3729-3735. [Crossref]

71. Cherubino P, Grassi FA, Bulghrtoni P, Ronga M (2003) Autologous chondrocyte implantation bilayer collagen membrane: A preliminary report. J Orthop Surg (Hong Kong) 11: 10-15. [Crossref]

72. Ebert JR, Fallon M, Smith A, Janes GC, Wood DJ (2015) Prospective clinical and radiographic evaluation of patellofemoral matrix-induced autologous chondrocyte implantatio. Am J Sports Med 43: 1362-1372. [Crossref]

73. Brittberg M (2010) Cell Carriers as the Next Generation of Cell Therapy for Cartilage Repair: A Review of the Martrix-induced Autologous Chondrocyte Implantation Procedure. Am J Sports Med 38: 1259-1271. [Crossref]

74. Marlovits S, Aldrian S, Wondrasch B, Zak L, Albercht C, et al. (2012) Clinical and Radiographic Outcomes 5 Years After Matrix-Induced Implantation in Patients With Symptomatic, Traumatic Chondral Defects. Am J Sports Med 20: 1-8. [Crossref]

75. Eriksen EF, Ringe JD (2012) Bone marrow lesions: a universal bone response to injury? Rheumatol Int 32: 575-584. [Crossref]

76. Sharkey PF, Cohen SB, Leinberry CF, Parvizi J (2012) Subchondral bone marrow lesions associated with knee osteoarthritis. Am J Orthop (Belle Mead NJ) 41: 413-417. [Crossref]

77. Cohen SB, Sharkey PF (2016) Subchondroplasty for Treating Bone Marrow Lesions. $J$ Knee Surg 29: 555-563. [Crossref]

78. Cohen SB, Sharkey PF (2012) Surgical treatment of osteoarthritis pain related to subchondral bone defects or bone marrow lesion: subchondralplasty. Tech Knee Surg 11: $170-175$.

79. Farr J II, Cohen SB (2013) Expanding applications of the subchondroplasty procedure for the treatment of bone marrow lesions observed on magnetic resonance imaging Oper Tech Sports Med 21: 138-143.

80. Chatterjuu D, McGee A, Strauss E, Youm T, Jazrami L (2015) Subchondral calcium phosphate is ineffective for bone marrow edema lesions in adults with advanced osteoarthritis. Clin Orthop Relat Res 473: 2334-2342. [Crossref]

Copyright: (C2017 Pettit T. This is an open-access article distributed under the terms of the Creative Commons Attribution License, which permits unrestricted use, distribution, and reproduction in any medium, provided the original author and source are credited. 